\title{
challenges
}

ISSN 2078-1547

www.mdpi.com/journal/challenges

Article

\section{Childhood Diarrhea Determinants in Sub-Saharan Africa: A Cross Sectional Study of Tiko-Cameroon}

\author{
Ayuk Betrand Tambe ${ }^{1, *}$, Leonie Dapi Nzefa ${ }^{2}$ and Nchang Allo Nicoline ${ }^{1}$ \\ 1 Catholic University of Central Africa, Yaoundé 5020, Cameroon; \\ E-Mail: nchangallonicole@yahoo.com \\ 2 Sweden-Cameroon Organization, Yaoundé 16355, Cameroon; E-Mail: dapileo@ hotmail.com \\ * Author to whom correspondence should be addressed; E-Mail: ayuk.betrand@ yahoo.com.
}

Academic Editor: Palmiro Poltronieri

Received: 25 May 2015 / Accepted: 18 September 2015 / Published: 23 September 2015

\begin{abstract}
Introduction: Diarrhea remains the second leading cause of death among children under five years globally. Nearly one in five child deaths, about 1.5 million each year, are due to diarrhea. It kills more young children than Acquired Immunodeficiency Syndrome (AIDS), malaria and measles combined. World Health Organization has accordingly underlined the need for epidemiological surveys of infantile diarrhea in all geographical areas. The main research objectives were to estimate the prevalence of diarrhea and identify factors associated with diarrheal diseases in Tiko city in Cameroon. Method: The present study was a cross-sectional community household survey which was conducted in Tiko town from 1st to 31st of August 2012. With the use of a questionnaire, a total of 602 households that had at least one child under five years of age were interviewed. Mothers/caregivers were questioned on the morbidity of diarrhea and the logistic regression model was employed to examine the determinants of childhood diarrhea. Both univariable and multivariable data analysis was performed using SPSS version 16.0. Results: The results of this study showed that the prevalence of diarrhea was $23.8 \%$ and children under 24 months were highly affected. We found children using the main toilet and other types of toilet facilities such as bushes, diaper, and streams (OR: $0.194 ; p<0.001,95 \% \mathrm{CI}$ ) and usage of narrow-mouth container for storage of drinking water (OR: 0.492; $p<0.001$, 95\% CI) less likely to suffer from diarrhea. In contrast, higher rates of diarrhea prevalence were seen in children from households with two or more siblings (OR: 1.222; $p<0.001,95 \% \mathrm{CI}$ ) and whose mothers/caregivers never
\end{abstract}


had the knowledge of safe sources of drinking water (OR: 1.849; $p<0.01,95 \% \mathrm{CI}$ ). Conclusion: Childhood diarrhea is a public health problem in Tiko city. Hence, interventions aimed at reducing the prevalence should take into consideration the integration of family planning activities in the prevention of childhood diarrhea and the deployed of health personals to educate the community to adopt a hygienic behavior. Future research on the topic should be qualitative inquiry to complement the quantitative nature of this study.

Keywords: risk factors; prevalence; morbidity; childhood diarrhea; Cameroon

\section{Introduction}

Diarrhea remains the second leading cause of death among children under five years globally [1]. Nearly one in five child deaths, about 1.5 million each year, are due to diarrhea [2,3]. It kills more young children than Acquired Immunodeficiency Syndrome (AIDS), malaria and measles combined [3]. Each year, an estimated 2.5 billion cases of diarrhea occur among children under five years of age, and estimates suggest that overall incidence has remained relatively stable over the past two decades [4]. It is estimated that, on average, each child under 5 years of age in developing countries suffers from three episodes of diarrhea per year [5]. In Africa, a child experiences five episodes of diarrhea per year and 800,000 children die each year from diarrhea and dehydration which account for 25 to $75 \%$ of all childhood diseases [6,7]. The number of childhood deaths only decreased by $4 \%$ in Africa from 2000 to 2008 , due to inadequate interventions and high poverty rate $[8,9]$.

The timely administration of oral rehydration salt (ORS), zinc tablets, vitamin A supplementation, safe water, good sanitation, and the use of antibiotics have proven to be both cost effective and efficacious as primary interventions for preventing diarrhea morbidity [10-13]. Notwithstanding, diarrhea prevalence has remained relatively stable over two decades as the interventions are not effectively implemented by many children [10,11]. For instance, only 39\% of infants less than 6 months are exclusively breastfed and only $35 \%$ of children with diarrhea receive oral rehydration therapy [14].

According to United Nations Children's Fund (UNICEF) annual report, 93,000 children less than five die every year in Cameroon [15]. Diarrheal disease is one of the major public health problems that cause excess morbidity and mortality in children in Cameroon [16,17]. Although diarrhea is recognized as a serious public health problem in Cameroon, very little comprehensive studies relating diarrhea-causing pathogens responsible for endemic diarrhea among Cameroon's children have been reported in the medical literature. World Health Organization (WHO) has accordingly underlined the need for epidemiological surveys of infantile diarrhea in all geographical areas. The main research objectives were to estimate the prevalence of diarrhea and identify factors associated with diarrheal diseases in Tiko city in Cameroon. 


\section{Method and Materials}

\subsection{Study Design and Setting}

The present study was a cross-sectional community household survey, which was conducted in Tiko town from 1st to 31st of August 2012. This is one of the administrative towns of Cameroon located in the South West region. Cameroon is one of the six Central African countries with an estimated population of 19.4 million inhabitants and a surface area of $475.440 \mathrm{~km}^{2}$ [18]. Tiko town consists of three health areas namely Tiko town, Holforth, and Likomba located in the Tiko health district (THD). This district is a rural-urban settlement that comprises one of the 18 health districts in the South-West region of the country. It has a surface area of 484 squares $\mathrm{km}$ with a total population estimated in 2010 at 134,647 inhabitants, making a population density of about 278 inhabitants per square kilometer. Four percent $(4 \%)$ of the total population consists of children less than 11 months, $18 \%$ consists of children less than 59 months. The district has recently suffered from the epidemic of cholera; one of the most acute forms of diarrheal diseases [17]

Data analyzed in this study was collected from selected households using a pretested, well-structured questionnaire. This morbidity survey instrument (questionnaire) was designed based on the results of preceding studies [17] in the chosen communities and the conceptual framework of known predictors of childhood diarrhea [17]. The questionnaire had four sections with an initial section designed to obtain basic information on the composition of the household visited. The second, third, and fourth were aimed to assess demographic and economic characteristics, environmental characteristics, and information on child diarrheal episodes for the preceding four weeks period respectively. If no child less than five years resided in the household, the interview ended. If the household had one child or more children less than five years of age, further information was obtained from a randomly selected child from the mother/caregiver above 18 years. The questionnaire was written in both French and English and was translated verbally to Pidgin-English for those who do not understand the two official languages.

\subsection{Sample Size and Sampling}

The estimated sample size of the study was 255 households calculated based on the $21 \%$ findings of demographic and health surveys 2011, confidence interval of 95\% (type value 1.96) and random error of $5 \%$ (type value of 0.05 ). Accurate determination of the minimum sample size is required for a given maximum error. The samples were selected using stratified and random sampling techniques. Initially, the health district was stratified into three health areas namely Holforth, Likomba, and Tiko town. One child under five years of age was randomly selected from each of the households for studying. The sample size of the study was doubled to have a narrower confidence interval and more significant results that can be generalized to the community [19].

\subsection{Data Collection and Quality Control}

Gastroenteritis (diarrhea) refers to the acute onset of enteric symptoms unrelated to existing health conditions, medication use, or other non-infectious causes, and is defined by its clinical picture, 
with symptom-based case definitions used to classify individuals as cases or non-cases. These case definitions are designed and used to estimate total morbidity, not as part of ongoing public health surveillance of enteric disease [20]. However, acute diarrhea was defined in our study as having three or more episodes of loose stools in any 24-h period within the past four weeks (28 days) before the interview. The definition excluded any type of chronic diarrhea already experienced by the respondent as a result of the underlying diseases such as Crohn's disease, irritable bowel syndrome, colitis, diverticulitis of large intestine, or another chronic illness with symptoms of diarrhea or vomiting or symptoms were due to pregnancy, excess alcohol, or food allergy, or medication use.

Since the duration of an episode of acute diarrhea is short, lasting usually a few days and rarely more than a week, an assumption for statistical analyses was that each case of acute diarrhea contributed to only one new episode of acute diarrhea in the preceding four weeks of the interview. Respondents who were ill prior to the 28-day observation period and still ill at the start of the observation were excluded from the cases. It was assumed that the prevalence of acute diarrhea and the population at risk were relatively stable throughout the year.

The results of the pre-test done on 20 families or households in Tiko were utilized to improve on the questionnaire; making sure the questions were very short, simple, took little time to complete and were understood by participants to prevent ambiguous answers. The questionnaires were administered by the authors together with five trained health workers. The questionnaires were filled on the spot by the administrators, and participants were clarified in case of any misinterpretation of a question. Moreover, the filled questionnaires were again checked at the end of the day for completeness, clarity and consistency.

\subsection{Data Analysis}

Statistical analysis was done using SPSS windows version 16.0 and included Pearson's Chi-square testing of all indicators because the dependent or independent variables had two or more categories. Descriptive statistics used to determine the prevalence of diarrhea (outcome variable). The frequencies, percentages and measures of central tendencies were obtained and displayed mainly on the tables and word expressions. The Pearson's Chi-square was used because the dependent or independent variables had two or more categories.

Logistic regression analysis was performed individually for three variable blocks, which estimated the effect socio-economic, environmental, and behavioral factors due to the dichotomous nature of dependent variable. The final model estimated the overall effect of the three blocks of variables. All models used simultaneous entry procedure to select the significant determinants. Variables that reached a likelihood ratio $p$-value $<0.05$ were included in the multivariable analysis to reduce excessive number of variables and resulting instability of the model. In addition, other variables that have been scientifically confirmed to influence diarrhea prevalence were also included in the model and a manual backward step wise method was used [21]. The best-fit model was determined by Bayesian Information Criterion (BIC) statistics of model comparison. Tolerance for the different predictors was used to check for collinearity. We also tested for potential confounding by removing and inserting plausible variables iteratively to assess for a change of $\geq 25 \%$ in odds ratios and we tested for significant interactions between all final variables in the model. The strength of association of 
determinant factors with the outcome variable was assessed using the odds ratio with a $95 \%$ confidence interval. Variables which were significant at $p$-value 0.05 level and $95 \% \mathrm{CI}$ were considered to be the determinant factors of childhood diarrhea.

\subsection{Ethical Consideration}

The ethical clearance and approval were obtained from the Cameroon National ethics Committee and Cameroon Ministry of Health through the district medical board of Tiko health district where the study took place. Approval permission and written consents were obtained from all participants in the study before collecting data, and all had complete right to withdraw from the study at any time without any explanation, and without negative consequences.

\section{Results}

\section{Characteristics of Subjects}

We initially planned to collect data on 255 children from each of the three health areas in Tiko Town which summed up to 765 children; but due to rejection of uncompleted questionnaires, withdrawal of consent by participants and the unwillingness to take part by mothers, we actually ended up with 283 (47\%) households from Holforth, 166 (27.6\%) household from Likomba and $153(25.4 \%)$ household from Tiko town which summed-up to 602 children. The response rates for Holforth, Likomba and Tiko town were $111 \%, 65.1 \%$ and $60 \%$, respectively. The mean age of these children was $32.7 \pm 19.0$ months. Majority of mothers/caregivers were married, of age 25-34 years $245(40.8 \%)$ and more than $67 \%$ of the mother/caretakers were above 24 years of age. The mean age of mothers/caregivers was $32.7 \pm 12.4$ years. Predominant number of the family heads interviewed $246(40.9 \%)$ had obtained primary educational level, $216(35.9 \%)$ were unskilled workers and 486 (48.0\%) earn a monthly average salary of 100-200 US Dollars (Table 1).

Majority of the participants 319 (53.0\%) lived in clean environment, 224 (37.2\%) fetched water from sources such as well, river, lake, stream or non-equipped source for cooking, cleaning of kitchen utensils and laundry, 275 (45.7\%) fetched drinking water from pipe borne taps, 176 (29.6\%) trekked for 6-15 $\mathrm{min}$ to fletch drinking water, 401 (66.6\%) of children used portable toilets facilities, $448(74.4 \%)$ of caregivers' had knowledge of safe source of water and $486(80.7 \%)$ of households used narrow-mouth containers for storage of water (Table 2). The prevalence of diarrhea in children aged less than five years was found to be $23.8 \%$ with children less than two years of age experienced the most of the disease (Figure 1). The mean duration of diarrhea stood at $2.9 \pm 1.7$ days. Holforth health area was exceptionally high with $25.8 \%$ prevalence rate. Most of the respondents (87.7\%) complained of having stomach cramps as the main symptom and a large number of the subjects (54.8\%) had the watery stool just from 1-2 days. Other symptoms experienced by participants included nausea, bloating, dehydration, fever and frequent urge to evacuate the bowels (Figure 2). More than half of the cases reported seeking no healthcare treatment and just 38 (26.6\%) seeking some form of healthcare (Table 3). 
Table 1. Demographic and socioeconomic characteristics of households in Tiko City, 2012.

\begin{tabular}{|c|c|c|c|c|}
\hline \multirow[b]{2}{*}{ Characteristics } & \multicolumn{3}{|c|}{ Health Area } & \multirow[b]{2}{*}{$\begin{array}{c}\text { Total } \\
(N=602)\end{array}$} \\
\hline & $\begin{array}{l}\text { Holforth } \\
(N=\mathbf{2 8 3})\end{array}$ & $\begin{array}{l}\text { Likomba } \\
(N=166)\end{array}$ & $\begin{array}{c}\text { Tiko Town } \\
(N=153)\end{array}$ & \\
\hline \multicolumn{5}{|l|}{ Mother/Caretaker } \\
\hline$\leq 24$ years & $79(27.9)$ & $42(25.5)$ & $37(24.2)$ & $158(26.3)$ \\
\hline 25-34 years & $100(35.3)$ & $75(45.5)$ & $70(45.8)$ & $245(40.8)$ \\
\hline 35 years and plus & $104(36.7)$ & $48(29.1)$ & $46(30.1)$ & $198(198)$ \\
\hline \multicolumn{5}{|l|}{ Marital status } \\
\hline Single & $41(14.5)$ & $21(12,7)$ & $20(13.1)$ & $82(13.6)$ \\
\hline Married & $213(75.3)$ & $137(82.5)$ & $116(75.8)$ & $466(77.4)$ \\
\hline Divorce & $03(1.1)$ & $01(0.6)$ & $02(1.3)$ & $06(1.0)$ \\
\hline Widow(er) & $26(9.2)$ & $07(4.2)$ & $15(1.8)$ & $48(8.0)$ \\
\hline \multicolumn{5}{|c|}{ Household head's Education level } \\
\hline No level & $19(6.7)$ & $5(3.0)$ & $03(2.0)$ & $27(4.5)$ \\
\hline Primary & $107(37.8)$ & $73(44.0)$ & $66(43.1)$ & $246(40.9)$ \\
\hline Secondary & $86(30.4)$ & $51(30.7)$ & $57(37.3)$ & $194(32.2)$ \\
\hline Tertiary & $71(25.1)$ & $37(22.3)$ & $27(17.6)$ & $135(22.4)$ \\
\hline \multicolumn{5}{|c|}{ Socio-professional Category } \\
\hline Unskilled worker & $108(38.2)$ & $97(58.4)$ & $63(41.2)$ & $268(44.5)$ \\
\hline Skilled worker & $67(23.7)$ & $46(27.7)$ & $36(23.5)$ & $149(24.8)$ \\
\hline Senior skill worker & $15(5.3)$ & $05(3.0)$ & $03(2.0)$ & $23(3.8)$ \\
\hline Head of an Enterprise & $10(3.5)$ & $01(0.6)$ & $0(0)$ & $11(1.8)$ \\
\hline Student & $0(0)$ & $02(1.2)$ & $01(0.7)$ & $3(0.5)$ \\
\hline Unemployed & $04(1.4)$ & $0(0)$ & $03(2.0)$ & $7(1.2)$ \\
\hline Other & $79(27.9)$ & $15(9.0)$ & $47(30.7)$ & $14(23.4)$ \\
\hline \multicolumn{5}{|c|}{ No. of Children <10years in the household } \\
\hline 1 & $98(34.6)$ & $98(60)$ & $55(35.9)$ & $213(35.4)$ \\
\hline 2 & $103(36.4)$ & $52(31.3)$ & $61(39.9)$ & $216(35.9)$ \\
\hline $3-4$ & $69(24.4)$ & $46(27.7)$ & $31(20.3)$ & $146(24.3)$ \\
\hline$\geq 5$ & $13(4.6)$ & $8(4.8)$ & $06(3.9)$ & $27(4.5)$ \\
\hline \multicolumn{5}{|c|}{ Month average salary (U.S. Dollars) } \\
\hline$<100$ & $101(35.7)$ & $46(27.7)$ & $41(26.8)$ & $188(31.2)$ \\
\hline $100-200$ & $115(40.6)$ & $87(52.4)$ & $87(56.9)$ & $289(48.0)$ \\
\hline $201-1000$ & $64(22.6)$ & $33(19.9)$ & $25(16.3)$ & $122(20.3)$ \\
\hline$>1000$ & $3(1.1)$ & $0(0.0)$ & $0(0.0)$ & $3(0.5)$ \\
\hline Total & $283(100)$ & $166(100)$ & $153(100)$ & $602(100)$ \\
\hline
\end{tabular}

Other $=$ Housewife, Businessmen (women)/hawker, Artist, Retired personnel. 
Table 2. Environmental characteristics of households in Tiko City 2012.

\begin{tabular}{|c|c|c|c|c|}
\hline \multirow[b]{2}{*}{ Characteristics } & \multicolumn{3}{|c|}{ Health Area } & \multirow{2}{*}{$\begin{array}{c}\text { Total } \\
(N=602)\end{array}$} \\
\hline & $\begin{array}{l}\text { Holforth } \\
(N=\mathbf{2 8 3})\end{array}$ & $\begin{array}{l}\text { Likomba } \\
(N=166)\end{array}$ & $\begin{array}{l}\text { Tiko Town } \\
(N=153)\end{array}$ & \\
\hline \multicolumn{5}{|l|}{ Habitat quality } \\
\hline Clean/security zone & $168(59.4)$ & $52(31.3)$ & $99(64.7)$ & $319(53.0)$ \\
\hline Dirty & $108(38.4)$ & $111(66.9)$ & $53(34.6)$ & $272(45.2)$ \\
\hline Swampy zone & $7(2.5)$ & $3(1.8)$ & $1(0.7)$ & $11(1.8)$ \\
\hline \multicolumn{5}{|l|}{ Water source for laundry and cooking } \\
\hline Tap pipe borne inside the household & $33(11.7)$ & $15(9)$ & $17(11.1)$ & $65(10.8)$ \\
\hline Tap pipe borne outside the household & $24(8.5)$ & $130(78.3)$ & $13(8.5)$ & $167(27.7)$ \\
\hline Tap public and other collective pipe borne & $3(1.1)$ & $13(7.8)$ & $9(5.9)$ & $25(4.2)$ \\
\hline Covered or equipped well sources & $65(23)$ & $1(0.6)$ & $54(35.3)$ & $120(19.9)$ \\
\hline Stream/rain water/non-equipped well sources & $158(55.8)$ & $7(4.2)$ & $60(39.3)$ & $225(37.4)$ \\
\hline \multicolumn{5}{|l|}{ Water source for drinking } \\
\hline Tap pipe borne inside/outside the household & $106(37.4)$ & $130(78.3)$ & $90(58.8)$ & $326(54.2)$ \\
\hline Tap public pipe borne & $17(6.0)$ & $2(1.2)$ & $0.0(0)$ & $19(3.2)$ \\
\hline Mineral water & $65(23)$ & $11(6.6)$ & $53(34.6)$ & $129(21.4)$ \\
\hline Other * & $95(33.6)$ & $23(13.9)$ & $10(6.6)$ & $128(20.7)$ \\
\hline \multicolumn{5}{|l|}{ Duration from Child's water source } \\
\hline $0 \mathrm{mins}$ & $48(17.0)$ & $23(13.9)$ & $23(15.0)$ & $94(15.6)$ \\
\hline $1-5$ mins & $30(10.6)$ & $104(62.7)$ & $44(28.8)$ & $178(29.6)$ \\
\hline $6-15$ mins & $50(17.7)$ & $21(12.7)$ & $24(15.7)$ & $95(15.8)$ \\
\hline $16-30 \mathrm{mins}$ & $54(19.1)$ & $11(6.6)$ & $38(24.8)$ & $103(17.1)$ \\
\hline $31-60 \mathrm{mins}$ & $26(9.2)$ & $7(4.2)$ & $21(13.7)$ & $54(9.0)$ \\
\hline$>60$ mins & $75(26.5)$ & $0(0)$ & $3(2.0)$ & $78(13)$ \\
\hline \multicolumn{5}{|l|}{ Child's toilet } \\
\hline Portable toilet/bucket & $171(60.4)$ & $130(78.3)$ & $100(65.4)$ & $401(66.6)$ \\
\hline Main toilet & $62(21.9)$ & $17(10.2)$ & $34(22.2)$ & $113(18.8)$ \\
\hline On soil around the compound/diapers/stream & $50(17.7)$ & $19(11.4)$ & $19(12.4)$ & $88(14.6)$ \\
\hline \multicolumn{5}{|l|}{ Child's water storage container } \\
\hline Pot/Basin & $31(11.0)$ & $52(31.1)$ & $33(21.6)$ & $116(19.3)$ \\
\hline Gallon/bottle & $252(89)$ & $114(68.7)$ & $120(78.4)$ & $486(80.7)$ \\
\hline Total & $283(100)$ & $166(100)$ & $153(100)$ & $602(100)$ \\
\hline
\end{tabular}

Other $*=$ other collective pipe borne, Pump wells/Boreholes, Well, Stream, Rain water. Habitat quality $=$ how clean or dirty or swampy is the household surrounding. 
Table 3. The health Characteristics of children under five years in Tiko, 2012.

\begin{tabular}{lcccc}
\hline \multirow{2}{*}{ Characteristics } & \multicolumn{3}{c}{ Health Area } & \multirow{2}{*}{ Total } \\
\cline { 2 - 4 } & $\begin{array}{c}\text { Holforth } \\
(\boldsymbol{N}=\mathbf{2 8 3})\end{array}$ & $\begin{array}{c}\text { Likomba } \\
(\boldsymbol{N}=\mathbf{1 6 6})\end{array}$ & $\begin{array}{c}\text { Tiko Town } \\
(\boldsymbol{N}=\mathbf{1 5 3})\end{array}$ & $(\boldsymbol{N}=\mathbf{6 0 2})$ \\
\hline $\begin{array}{l}\text { Watery stool 3-4 times in } \\
\text { past Four (4) weeks }\end{array}$ & & & & \\
\hline Yes & $73(25.8)$ & $36(21.7)$ & $34(22.2)$ & $143(23.8)$ \\
No & $210(74.2)$ & $130(78.3)$ & $119(77.8)$ & $459(76.2)$ \\
\hline Symptoms & & & & \\
\hline Stomach cramps & $61(80.3)$ & $33(91.7)$ & $34(100)$ & $128(87.7)$ \\
Headache & $15(19.7)$ & $4(19.7)$ & $9(26.5)$ & $28(19.2)$ \\
Other* & $26(34.2)$ & $10(27.8)$ & $7(20.6)$ & $43(29.5)$ \\
\hline Duration of diarrhea & & & & \\
\hline 1-2 days & $43(56.6)$ & $20(55.6)$ & $17(50.0)$ & $80(54.8)$ \\
3-5days & $18(23.7)$ & $11(30.6)$ & $12(35.3)$ & $41(28.1)$ \\
$>5$ days & $15(19.7)$ & $5(13.9)$ & $5(14.7)$ & $25(47.1)$ \\
\hline Health seeking behavior & & & & \\
\hline No treatment & $42(57.5)$ & $21(58.8)$ & $16(47.1)$ & $79(55.2)$ \\
Medical center/pharmacy & $18(24.7)$ & $11(30.6)$ & $09(26.5)$ & $38(26.6)$ \\
Home care & $08(11.0)$ & $03(08.3)$ & $07(20.5)$ & $18(12.6)$ \\
Traditional & $05(06.8)$ & $01(02.8)$ & $02(05.9)$ & $08(06.0)$ \\
\hline
\end{tabular}

Other $*$ = nausea, bloating, dehydration, fever and frequent urge to evacuate the bowels.

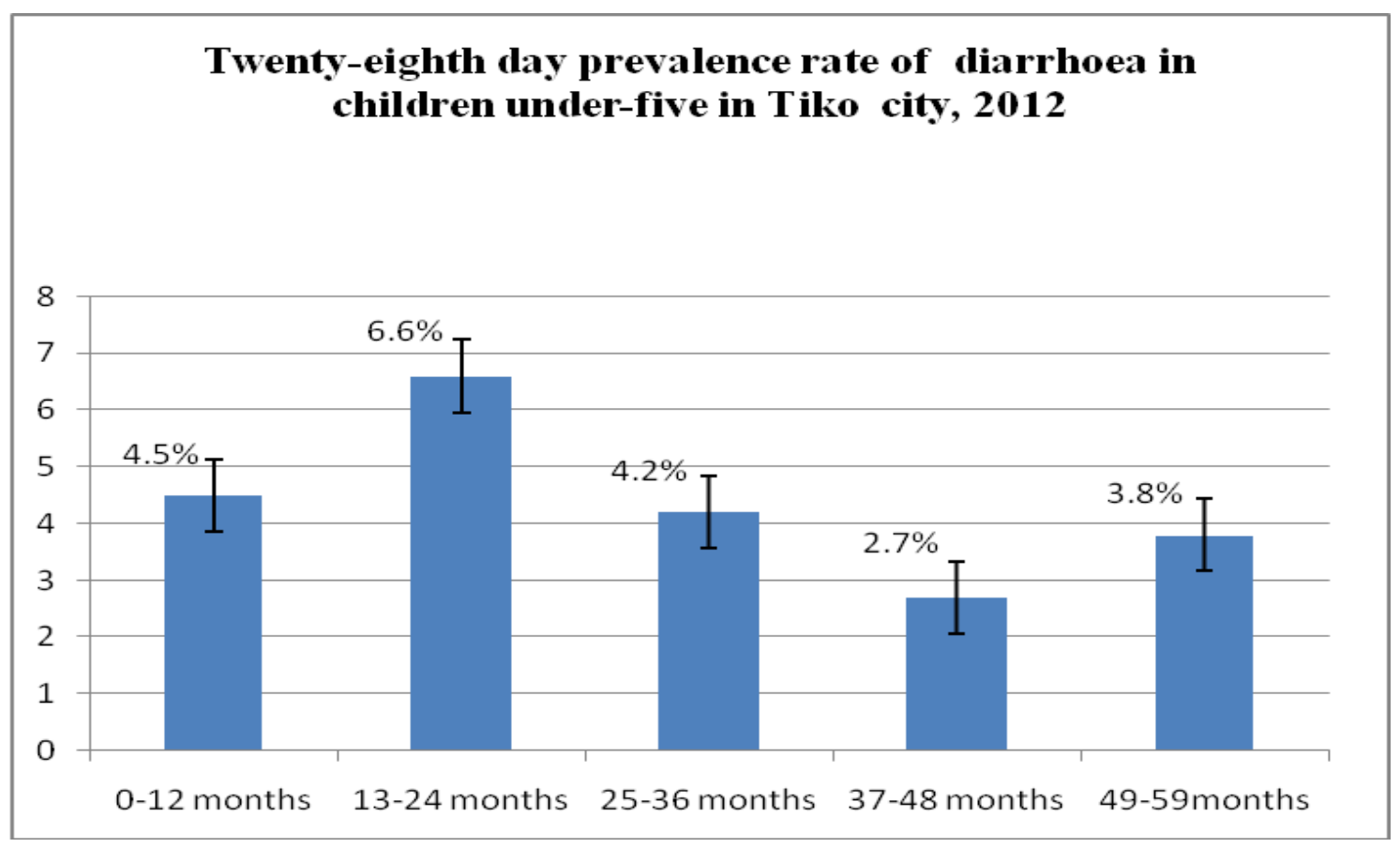

Figure 1. Twenty-eighth day prevalence rate of diarrhea in children under-five in Tiko City, $2012(n=602)$. 


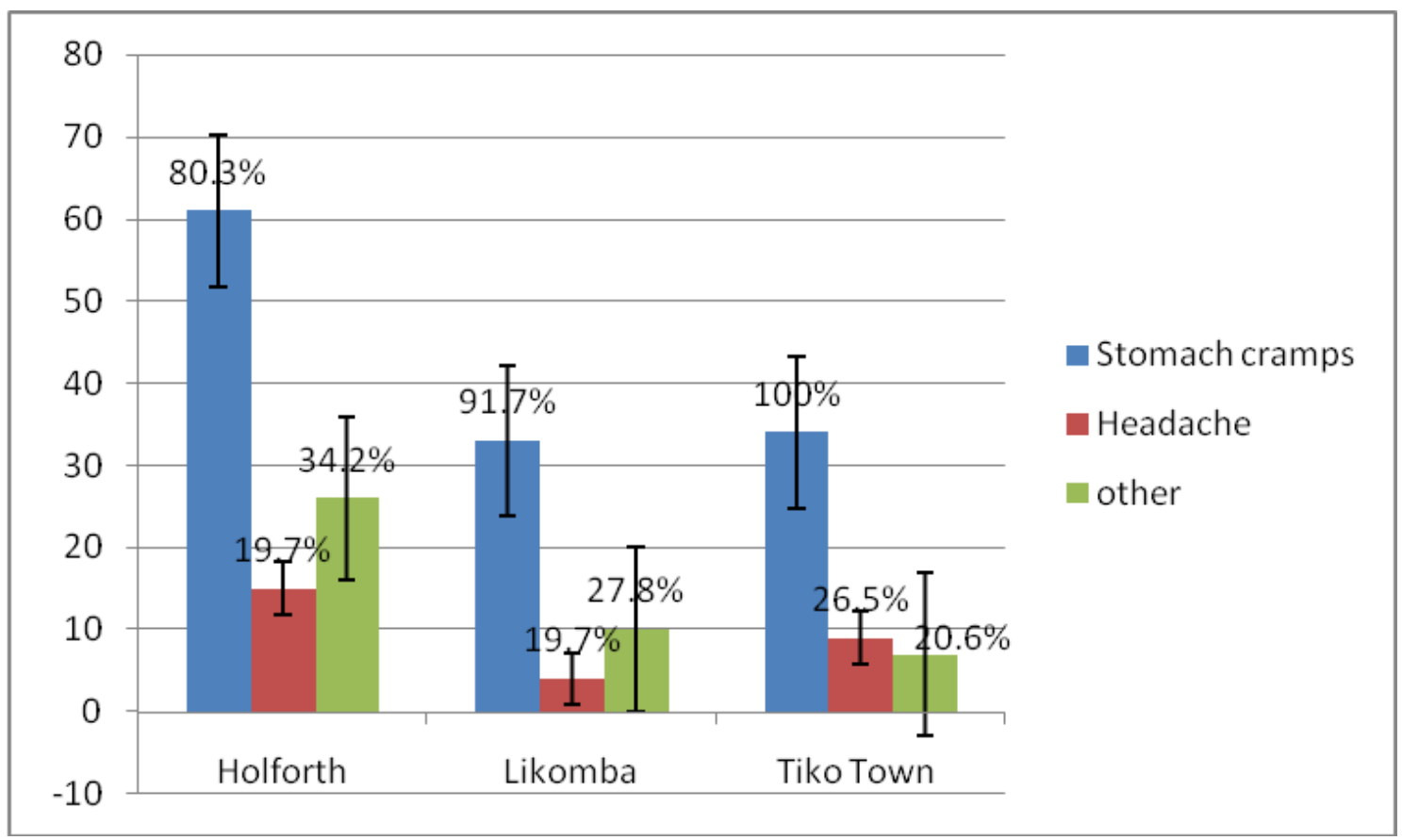

Figure 2. Diarrhea symptoms experienced by participants per health area in Tiko city 2012.

A number of risk factors found significant in our univariable analysis include the number of children under ten years in the household (siblings), duration trekked to fletch water, quality of water use for drinking, quality of water use for cooking, cleaning of kitchen utensils and laundry, quality of the environment in which the children lived, the caregiver's knowledge of safe source of water and type of container use for the storage of water were significant at $p<0.001$ while age of the children, and child's toilet facility were significant at $p<0.05$.

The association of these risk factors and diarrheal morbidity in children less than five years of age in Tiko was evaluated using multivariable analysis. Among all variable analyzed, only number of children under 10 years living in a household, the child's toilet facility (where the child defecates), drinking water storage container and the caregiver's knowledge of safe source of water were significantly associated with diarrhea.

We found children using the main toilet and other types of toilet facilities such as bushes, diaper, and streams (OR: 0.194; $p<0.001,95 \% \mathrm{CI}$ ) and usage of narrow-mouth container for storage of drinking water (OR: $0.492 ; p<0.001,95 \% \mathrm{CI}$ ) less likely to suffer from diarrhea.

In contrast, higher rates of diarrhea prevalence were seen in children from households with two or more siblings (OR: 1.222; $p<0.001,95 \%$ CI) and whose mothers'/caregivers' never had the knowledge of safe source of drinking water (OR: $1.849 ; p<0.01,95 \% \mathrm{CI})$ (Table 4). 
Table 4. The distribution of children less than five of age with Diarrhea according to their Environmental and behavioral characteristics in Tiko city 2012.

\begin{tabular}{|c|c|c|c|}
\hline Characteristics & Proportion & OR & $p$ at $95 \% \mathrm{CI}$ \\
\hline Number of children in household & $* * *$ & $* * *$ & \\
\hline 1 & 23.8 & Ref & \multirow{4}{*}{$p<0.05$} \\
\hline 2 & 37.8 & $1.222 * * *$ & \\
\hline $3-4$ & 30.8 & 0.577 & \\
\hline$\geq 5$ & 7.7 & 0.626 & \\
\hline Child's toilet & $* * *$ & $* * *$ & \multirow{4}{*}{$p<0.05$} \\
\hline Portable toilet/bucket & 72.0 & Ref & \\
\hline Main toilet & 7.7 & $0.528 *$ & \\
\hline Other * & 20.3 & $0.194 * * *$ & \\
\hline Child's water storage container & $* * *$ & $* * *$ & \\
\hline Pot/Basin & 28.0 & Ref & \multirow{2}{*}{$p<0.05$} \\
\hline Gallon/bottle & 72.0 & $0.429 * * *$ & \\
\hline Do you think your source of Water is safe? & $* * *$ & $* *$ & \\
\hline Yes & 63.6 & Ref & \multirow{2}{*}{$p<0.05$} \\
\hline No & 36.4 & $1.849 * *$ & \\
\hline
\end{tabular}

\section{Discussion}

This study provides thorough information about household characteristics in an urban setting of Tiko city and their interrelation with diarrhea prevalence among the children aged five years population. Our study found that, the prevalence of diarrhea in children aged less than five years was higher (23.8\%) as compared to the $21 \%$ percent survey results carried out by the Cameroon National institute of Statistics [17]. A recent cross-sectional study conducted in Indigenous Batwa Pygmy population in southwestern Uganda to assess the burden and determinants of self-reported acute gastrointestinal illness within the previous 14 days showed a lower prevalence rate of $6 \cdot 17 \%$ [22]. This finding is important because it has implications on the implementation of healthcare programs to address child health problems in Cameroon. The Integration of these programs needs to be intensified for effective reduction of childhood morbidity. The disparity in prevalence rates may be due to seasonal variation. The data of the present study was collected in August; the heart of rainy season, when diarrhea prevalence has been reported to be high [23,24]. During this period water sources are easily polluted, these sources of water are mostly utilized by households for washing of hands, household activities and even drinking especially for those using streams or boreholes.

Our findings found a positive association between the number of children under 10 years in a household and diarrhea prevalence rates. It is in consonance with a number of cross sectional studies conducted in Ethiopia [25], Niger [26] and Nigeria [27], and a case-control study conducted in Cameroon [28]. These studies have also reported a similar association between children family size and diarrhea morbidity. In addition, another study conducted in Pakistan with the goal to investigate the socio-economic determinants of diarrhea morbidity, also indicated that number of children born was a predictor of diarrhea among children aged less than five years [29]. This is 
probably because as the number of children in a household increases, there will be a greater number of persons to visit the drinking container thus increasing the probability of dirtying the water, deteriorate the hygienic condition, which in turns increases the chances of contact with pathogens. Secondly, as the number of children increases, the usage of water also increases, thus it might be costly to sustain the increased with bottled water leading to the resorting to the different sources of water available at their disposal. It has been reported that it is difficult for the caregiver to care for a large number of children [30].

The type of toilet facility used by the children has been demonstrated to be associated with the incidence of diarrhea morbidity [31-34]. A household survey carried out in Rural Burundi to explore diarrhea prevalence in children less than five years of age showed that in the absence of toilet facility, children from mothers who had no education had a very high risk of developing diarrhea than children from mothers [31,35]. A randomized study conducted in Western Kenya on impact of school-based hygiene promotion and sanitation intervention on pupil hand contamination [33], and in Nepal [34] have also confirmed the association between toilet facility and diarrhea morbidity. This finding is in agreement with the later mentioned studies. Diarrhea is generally due to exposure to diarrhea-causing organisms which is mainly found in feces. Therefore, this perhaps depends on defecation habits and personal hygiene of the household [36,37].

The importance of water storage container in transmission of diarrhea-causing pathogens has been documented in a previous study [35]. The usage of narrow-mouth container for storage of drinking was also found in our study to be protective factor for diarrhea morbidity. This is in agreement with a study conducted in Southwest Ethiopia that have demonstrated significantly higher prevalence of diarrhea in children from households where water is obtained from storage container by dipping than in those where water is obtained by pouring [35].

In this study, there was significant association between knowledge of safe drinking water and diarrhea morbidity. Hygiene related studies investigating the effects of caregivers' knowledge of safe drinking water on the incidence of diarrhea have also established this association [38,39]. This is most likely due to the fact that those who are informed of the safe source are likely to provide their children with water from safe sources or use safe sources for household activities as compared to those who do not know. Thus, their children will have a lesser chance of having diarrhea compared to their counterparts who lack the knowledge. In sub-Saharan Africa, caregivers are the closest persons to the children and decide on the type of water to be taken by the children. Hence, it is not surprising as noted in this study that, caregivers' knowledge of safe drinking water is associated diarrhea morbidity.

The study showed that diarrhea was significantly associated with children's age in the univariable analysis. However, this association disappeared at the level of the multivariable analysis. This finding is analogous with a hospital based study carried out in Ghana on major parasitic causes of childhood diarrhea also confirmed this association [40]. Another cross-sectional study conducted in Eastern Ethiopia studying the prevalence of diarrhea and associated risk factors among children less than five years of age reported that diarrhea was significantly associated with children in the age groups 6-11 months and 12-23 months compared to children aged above 35 months [41].

This paper demonstrated that the quality of drinking water used by households was an independent risk factor of diarrhea. However, this confirmed the findings of a study conducted in rural India with the aim to assess the effect of piped water on the prevalence of childhood diarrheal [42]. The study 
showed that a child gains health from access to pipe water (safe water). They went further to show that, access to piped water significantly reduces diarrhea prevalence and duration. This is most likely due to the existing scientific knowledge that most diarrhea causing microorganisms are mainly transmitted through water. Treatment of water helps to kill these organisms as in the case of pipe borne water. Therefore, untreated water still contain vibrant strains of these microorganisms which when taken into the system will certainly cause the individual to be sick.

Environmental quality was found to be an independent risk factor of diarrhea with the association not observed when other factors were controlled in the final model. However other environmental-based studies have established the association [1,35]. Our finding also contradicts a household survey carried on Rural Burundi which demonstrated that access to improved environmental sanitation has no significant effect on diarrhea prevalence [31].

Some of the shortcomings of our study include sampling and measurement errors, recall and misclassification bias, self-reported issues and lack of pathogen testing. In addition, the information obtained from this cross-sectional study is of diarrhea prevalence in the four weeks previous to the study, which does not account for seasonality. Hence, data are not comparable either across sites or over time. Some of the above mentioned shortcomings were reduced by asking several questions on a particular problem. In addition, the strength of our study lies in the unique characteristics of the Demographic Health Survey (DHS). DHS is nationally representative, and allows for findings to be generalized across the entire country.

\section{Conclusions}

In sum, the prevalence of diarrhea in children under five years is quite high in Tiko city with children younger than two years of age being the most affected. The availability of children under 10 years in a household, the child's toilet facility, drinking water storage container and the caregiver's knowledge of safe source of water seem to play significant role diarrhea morbidity. Hence, interventions aimed at reducing the prevalence should take into consideration the integration of family planning activities in the prevention of childhood diarrhea and the deployed of health personals to educate the community to adopt a hygienic behavior. Future research on the topic should be qualitative inquiry to complement the quantitative nature of this study.

\section{Acknowledgments}

We sincerely thank the following persons for their contributions in making this work a success. They include: Rosine Mayap Nzietchueng, Ashuntantang Adolf Enow-mbi, Bechemagbor Samuel Nkeng, Bechemagbor Emilia Bechem, Nforndip Pauline Manyi, Mforndip Suzanne, Ayuk Dorine Tiku, Ashuntantang Antoinette Eyere, Ayuk Martin Tambe, Marie Oben, Mforndip Junior Eta, and Beteck George Besong for their unlimited assistance which is very much appreciated. This research was financially supported by Sweden-Cameroon Organization. 


\section{Author Contributions}

All authors took part in the conception, extraction of data, statistical analysis, reading and approval of the final manuscript prior to submissions.

\section{Conflicts of Interest}

The authors declare no conflict of interest.

\section{Abbreviations}

W.H.O: World Health Organization; SPSS: Statistical Package for the Social Science; ORS: Oral rehydration salts; DHS: Demographic and Health Surveys; OR: Odd Ratio; SSA: Sub-Saharan Africa; RGPH: "Recensement general de la population et de l'habitat".

\section{References}

1. Pond, K.; Rueedi, J.; Pedley, S. Microrisk: Pathogens in Drinking Water Sources; Robens Centre for Public and Environmental Health: Guildford, UK, 2004.

2. Bryce, J.; Boschi-Pinto, C.; Shibuya, K.; Black, R.E. WHO estimates of the causes of death in children. Lancet 2005, 365, 1147-1152.

3. UNICEF/WHO. Diarrhea: Why Children are Still Dying and What Can be Done; World Health Organisation: Geneva, Switzerland, 2009.

4. Boschi-Pinto, C.; Velebitb, L.; Shibuyac, K. Estimating child mortality due to diarrhea in developing countries. Bull. World Health Organ. 2008, 86, 710-717.

5. Kosek, M.; Bern, C.; Guerrant, R.L. The global burden of diarrheal disease, as estimated from studies published between 1992 and 2000. Bull. World Health Organ. 2003, 8, 197-204.

6. Woldemichael, G. Diarrheal morbidity among young children in Eritrea: Environmental and socioeconomic determinants. J. Health Popul. Nutr. 2001, 19, 83-90.

7. World Health Organization. Child Health Research Project: Childhood Diarrhea in Sub-Saharan Africa; World Health Organisation: Geneva, Switzerland, 1998.

8. Black, R.E.; Cousens, S.; Johnson, H.L.; Lawn, J.E.; Rudan, I.; Bassani, D.G.; Jha, P.; Campbell, H.; Walker, C.F.; Cibulskis, R.; et al. Global, regional, and national causes of child mortality in 2008: A systematic analysis. Lancet 2010, 375, 1969-1987.

9. Bouree, P. Tropical diarrhea: Consequences of poverty. Presse Med. 2007, 36, 683-685.

10. Bhandari, N.; Mazumder, S.; Taneja, S.; Dube, B.; Agarwal, R.C.; Mahalanabis, D.; Fontaine, O.; Black, R.E.; Bhan, M.K. Effectiveness of zinc supplementation plus oral rehydration salts compared with oral rehydration salts alone as a treatment for acute diarrhea in a primary care setting: A cluster randomized trial. Pediatrics 2008, 121, 1279-1285.

11. Bhatnagar, S.; Bahl, R.; Sharma, P.K.; Kumar, G.T.; Saxena, S.K.; Bhan, M.K. Zinc with oral rehydration therapy reduces stool output and duration of diarrhea in hospitalized children: A randomized controlled trial. J. Pediatr. Gastroenterol. Nutr. 2004, 38, 34-40. 
12. Fischer Walker, C.L.; Fontaine, O.; Young, M.W.; Black, R.E. Zinc and low osmolarity oral rehydration salts for diarrhea: A renewed call to action. Bull. World Health Organ. 2009, 87, 780-786.

13. Ram, P.K.; Choi, M.; Blum, L.S.; Wamae, A.W.; Mintz, E.D.; Bartlett, A.V. Declines in case management of diarrhea among children less than five years old. Bull. World Health Organ. 2008, 86, doi:10.1590/S0042-96862008000300024.

14. UNICEF \& WHO. Ending Preventable Child Deaths from Pneumonia and Diarrhea by 2025: The integrated Global Action Plan for Pneumonia and Diarrhea (GAPPD); World Health Organisation: Geneva, Switzerland, 2013.

15. United Nations Children's Fund, UNICEF. Levels and Trends in Child Mortality. Available online: http://www.childinfo.org/files/Child_Mortality_Report_2010.pdf (accessed on 15 April 2013).

16. Yongsi, H.B.; Gerard, S.; Thouez, J.P. Health risks associated with faces cleansing methods in Yaounde, Cameroon. Nat. Sci. Soc. 2008, 16, 3-12.

17. Demographic and Health Surveys. Enquête Démographique et de Santé et à Indicateurs Multiples EDS-MICS 2011; National Institute of Statistics: Yaoundé, Cameroon, 2011. (in French)

18. National Institute of Statistics. Bureau Central des Recensements et des Etudes de la Population. La population du Cameroun en 2010; National Institute of Statistics: Yaoundé, Cameroon, 2010.

19. Amin, M.E. Social Sciences Research: Conception, Methodology and Analysis Includes Bibliographical References and Indexes; Makerere University Printer: Kampala, Uganda, 2005.

20. Majowicz, S.E.; Hall, G.; Scallan, E.; Adak, G.K.; Gauci, C.; Jones, T.F.; O’Brien, S.O.; Henao, O.; Sockett, P.N. A common, symptom-based case definition for gastroenteritis. Epidemiol. Infect. 2008, 136, 886-894.

21. Hosmer, D.; Lemeshow, S. Applied Logistic Regression, 2nd ed.; Wiley: New York, NY, USA, 2000; pp. 92-95.

22. Clark, S.; Berrang-Ford, L.; Lwasa, S.; Namanya, D.B.; Edge, V.L.; IHACC Research Team; Harper, S. The burden and determinants of self-reported acute gastrointestinal illness in an indigenous Batwa Pygmy population in Southwestern Uganda. Epidemiol. Infect. 2015, 143, 2287-2298.

23. Gaigbe, T.V. Seasonality and cause of infant deaths in Yaounde. Ann. IFORD 1988, 12, 97-126.

24. Ako, A.A.; Nkeng, G.E.; Takem, G.E. Water quality and occurrence of water-borne diseases in the Douala 4th District, Cameroon. Water Sci. Technol. 2009, 59, 2321-2329.

25. Mihrete, T.S.; Alemie, G.A.; Teferra, A.S. Determinants of childhood among under five children in Benishangul Gumuz Regional State, North West Ethiopia. BMC Pediatr. 2014, 14, doi:10.1186/1471-2431-14-102.

26. Page, A.; Hustatache, S.; Luquero, F.; Djibo, A.; Laouali, M.; Grais, R. Health care seeking behavior for diarrhea in children under 5 in rural Niger: Results of a cross-sectional survey. BMC Public Health 2011, 11, doi:10.1186/1471-2458-11-389.

27. Yilgwan, C.S.; Okolo, S.N. Prevalence of diarrhea disease and risk factors in Jos University Teaching Hospital, Nigeria. Ann. Afr. Med. 2012, 11, 217-221.

28. Yongsi, H.B. Pathogenic microorganisms associated with childhood diarrhea in low-and-middle income countries: Case study of Yaoundé-Cameroon. Int. J. Environ. Res. Public Health 2008, 5, 213-229. 
29. Arif, A.; Naheed, R. Socio-economic determinants of diarrhea morbidity in Pakistan. Acad. Res. Int. 2012, 2, 398-432.

30. El-Gilany, A.H.; Hammad, S. Epidemiology of diarrheal diseases among children under age 5 years in Dakahlia, Egypt. East. Mediterr. Health J. 2005, 11, 762-775.

31. Diouf, K.; Tabatabai, P.; Rudolph, J.; Marx, M. Diarrhea prevalence in children under five years of age in rural Burundi: An assessment of social and behavioral factors at the household level. Glob. Health Action 2014, 7, doi:10.3402/gha.v7.24895.

32. Amy Quinn, A.B. Likelihood in Ghanaian Children: A Study of the Association between Diarrhea and Water and Sanitation Infrastructure. Master Thesis, Georgetown Public Policy Institute, Washington, DC, USA, 2009.

33. Greene, L.E.; Freeman, M.C.; Akoko, D.; Saboori, S.; Moe, C.; Rheingans, R. Impact of a school-based hygiene promotion and sanitation intervention on pupil hand contamination in Western Kenya: A cluster randomized trial. Am. J. Trop. Med. Hyg. 2012, 87, 385-393.

34. Ansari, M.; Ibrahim, M.I.; Hassali, M.A.; Shankar, P.R.; Koirala, A.; Thapa, N.J. Mothers' beliefs and barriers about childhood diarrhea and its management in Morang district, Nepal. BMC Res. Notes 2012, 5, doi:10.1186/1756-0500-5-576.

35. Teklemariam, S.; Getaneh, T.; Bekele, F. Environmental determinants of diarrhea morbidity in under-five children, Keffa-Sheka Zone, Southwest Ethiopia. Ethiop. Med. J. 2000, 38, 27-34.

36. Lindstrand, A.; Bergstrom, S.; Rosling, H.; Rubenson, B.; Stenson, B.; Tylleskar, T. Global Health -An Introductory Textbook; Narayana Press: Copenhagen, Denmark, 2006; p. 325.

37. Motarjemi, Y.; Käferstein, F.; Moy, G.; Quevedo, F. Contaminated weaning food: A major risk factor for diarrhea and associated malnutrition. Bull. World Health Organ. 1993, 71, 79-92.

38. Root, G.P.M. Sanitation, community environment and childhood diarrhea in rural Zimbabwe. $J$. Health Popul. Nutr. 2001, 19, 73-82.

39. Ghosh, S.; Sengupta, P.G.; Gupta, D.N.; Mondal, S.K.; Goswami, M.; Bhattacharya, S.K.; Sircar, B.K. Maternal knowledge on risk behavioural practices and its association with diarrhea in a rural community of West Bengal, India. J. Commun. Dis. 1998, 30, 251-255.

40. Nkrumah, B.; Nguah, S.B. Giardia lamblia: A major parasitic cause of childhood diarrhea in patients attending a district hospital in Ghana. Parasit. Vectors 2011, 4, doi:10.1186/1756-3305-4-163.

41. Bezatu, M.; Yemane, B.; Alemayehu, W. Prevalence of diarrhea and associated risk factors among children under-five years of age in Eastern Ethiopia: A cross-sectional study. Open J. Prev. Med. 2013, 3, 446-453.

42. Jalan, J.; Ravallion, M. Does piped water reduce diarrheal disease for children in rural India? $J$. Econom. 2001, 152, 153-173.

(C) 2015 by the authors; licensee MDPI, Basel, Switzerland. This article is an open access article distributed under the terms and conditions of the Creative Commons Attribution license (http://creativecommons.org/licenses/by/4.0/). 